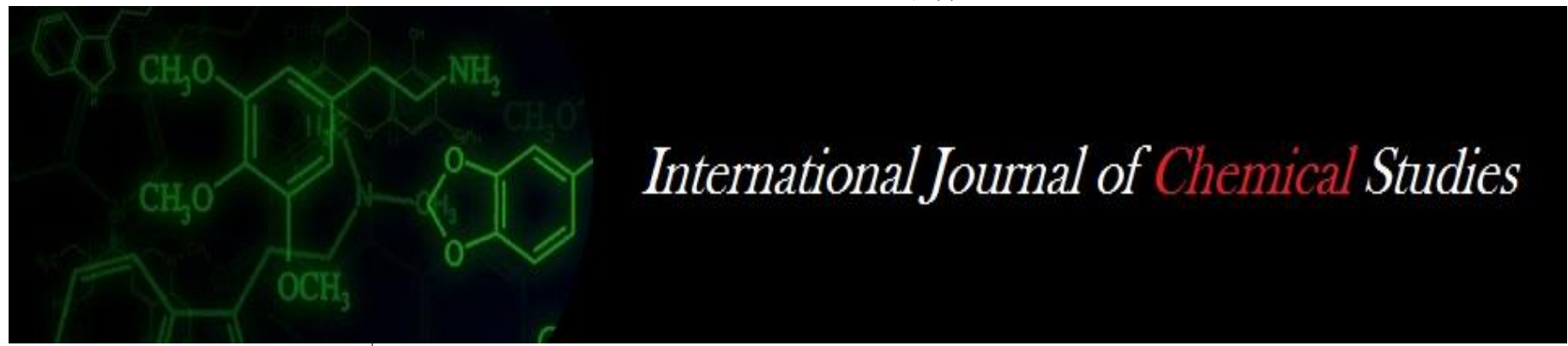

P-ISSN: 2349-8528

E-ISSN: 2321-4902

IJCS 2020; 8(1): 2242-2245

(C) 2020 IJCS

Received: 22-11-2019

Accepted: 24-12-2019

\section{Muzaffar Hasan}

Scientist, ICAR-CIAE, Bhopal, Madhya Pradesh, India

\section{Ajesh Kumar V}

Scientist, ICAR-CIAE, Bhopal, Madhya Pradesh, India

Chirag Maheshwari

Scientist, ICAR-CIAE, Bhopal,

Madhya Pradesh, India

\section{S Mangraj}

Scientist, ICAR-CIAE, Bhopal, Madhya Pradesh, India
Corresponding Author: Muzaffar Hasan

Scientist, ICAR-CIAE, Bhopal, Madhya Pradesh, India

\section{Biodegradable and edible film: A counter to plastic pollution}

\section{Muzaffar Hasan, Ajesh Kumar V, Chirag Maheshwari and S Mangraj}

DOI: https://doi.org/10.22271/chemi.2020.v8.i1ah.8606

\section{Abstract}

The reckless use of plastic is becoming a major threat to the environment. Therefore, reduction of plastic pollution is becoming a primary priority of every nation around the globe. Scientific community across the world has been searching for an alternative to plastic for many years. Food industry globally contributes a major share of the total plastic waste produced. Use of biodegradable and edible films is an alternate for many of the existing use of plastic packages in food and allied industry. Although it is not sufficient to completely curb the problem, may be able to play an important role in plastic pollution. More focus on edible and biodegradable packaging research is the need of the hour to make them a complete alternative for plastic packaging.

Keywords: Biodegradable, edible film, plastic pollution

\section{Introduction}

Today we are living in an era called it "Plastic age" (Thompson et al., 2009b) [9]. The ubiquitous presence of plastic has some strong and valid reasons like its durability, flexibility, and cheapness spread it around the globe. However, now it is not hidden that too much use of plastic and disposing of plastic is becoming the major threat to the environment of the earth. Unnecessary use of plastic, improper dumping, excessive use of single-use plastics and lack of awareness are the factors responsible for today's world condition of ecosystems. Plastic pollution not only affects the land and terrestrials' animals but also causes harm to marine animals and pollutes our water sources (fig. 1). Even though, the agricultural sector is also not untouched by this plastic pollution. It is postulated that excessive use of plastic in agriculture and leaching of microplastic (plastic particle size $<5 \mathrm{~mm}$ ) in the soil causing soil degradation (Steinmetz et al., 2016) ${ }^{[8]}$. Today every nation is trying to minimize the use of plastics and improving the conditions of water sources.

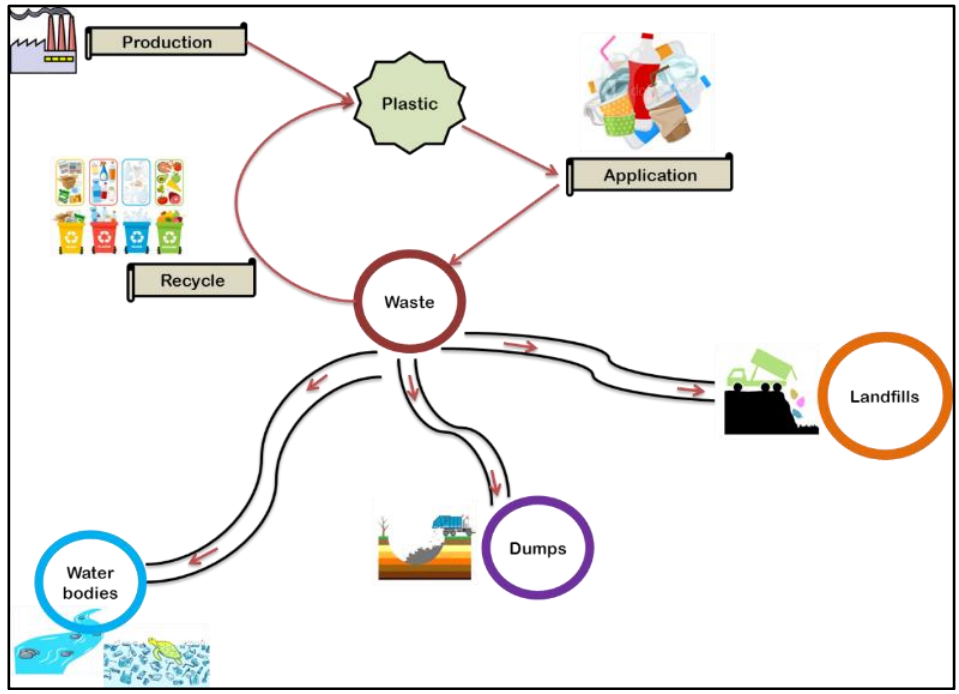

Fig 1: Global plastic flow 
Currently, plastic production is reaching towards 350million tons per year (Plastic Europe 2018) ${ }^{[6]}$. Relentless use of plastics in the various industry produces an enormous amount of plastic wastes which became a serious threat to the environment. The plastic waste either go for recycling and help to produce other new plastics or remain waste. The mismanagement of remaining plastic wastes consequently pollutes our land and our water sources which ultimately cause harm to the living organism of land and ocean. Among several industries, the food packaging industry is also a major plastic waste-producing industry. People around the world are using plastic bottles, plastic spoons, wrapper, plates and so many things which made up of plastics (fig.2).
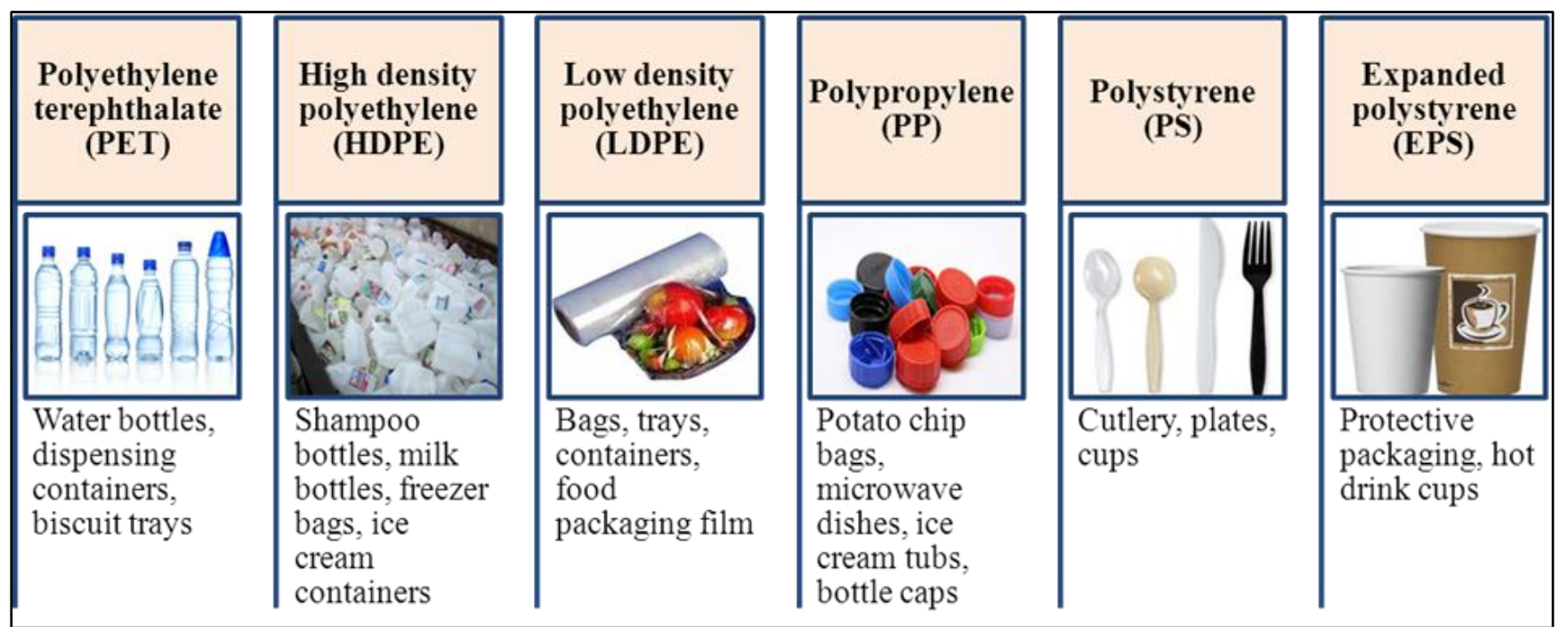

Fig 2: Showing the most common plastic wastes found in the environment.

Biodegradable films and edible films can decompose easily by the environment. Substitution of plastic or polythene through biodegradable film and edible film in food and other applicable industry might be helpful to reduce the plastic pollution significantly. Edible film and edible coatings are made up of protein, polysaccharide, lipids and other substitutes.

\section{Use of plastics and plastic pollution-}

There is a tremendous growth in the world population and the estimated population in 2019 is 7.7 billion will rise to 9.7 billion in 2050. So, having this in mind one can expect the amount of the garbage we human produce will see a sharp increase in the present and as well as in the future. Presently, according to an on-the-go lifestyle, there are lots of disposable items in use and in demands such as food packing material, household items and so on. Easy and cheap accessibility of plastic made it a material, which was utilized everywhere but at the same time, this brings a darker side of this material, every year around the globe $40 \%$ of plastic produced is single-use plastic. Plastic production in 1950 was just 2.3 million tons whereas this was increased to 448 million tons in 2015, and this will rise to extraordinary numbers in 2050 where it is expected to be double what we are producing right now. This creates a new topic where rather discussing its utilization we have to discuss how to dispose of it. Now all the countries are concerned about plastic pollution, a condition where plastic accumulates in such a vast amount that it becomes a problem for the environment, humans, plants, and animals.

While it seems easy to clean up the plastic trash just by implementing the recycle principle that is collect it and reutilize it one or other form but the real truth is plastic pollution range from large plastic trash to microplastic and plastic microfibers, which were even reported in drinking water and the air we breathe. In the present situation, only $9 \%$ of the plastic produced is recycled, $12 \%$ incinerated and the remaining $79 \%$ either goes to landfill or remains as a pollutant in the environment.

\section{Biodegradable film}

Biodegradable refers to the ability of materials to break down and return to nature within a short time after disposal typically a year or less. Natural polymers derived from agricultural products (such as starch, proteins, cellulose and plant oils) are the major resource for developing renewable and biodegradable polymer materials. Natural polymers derived from agricultural products (such as starch, proteins, cellulose and plant oils) are the major resource for developing renewable and biodegradable polymer materials.

Biomaterials (biopolymers) are polymers produced from renewable sources. Biopolymers are manufactured from plant raw materials, in the first place, but in recent times from the animal sources also. Their main feature is their biodegradability. They are classified in many ways such as chemical structure, origin, methods of synthesis, costeffectiveness and application. Conventional polymers are not biodegradable because of long chains of molecules that are too big and too well connected to each other to make them able to separate the microorganisms to break down. Unlike conventional, polymers made from natural plant materials from wheat, potato or corn starches have molecules that are easily microbiologically degradable. The biodegradable film tries to mimic biomass life cycle as shown in figure 3 . 


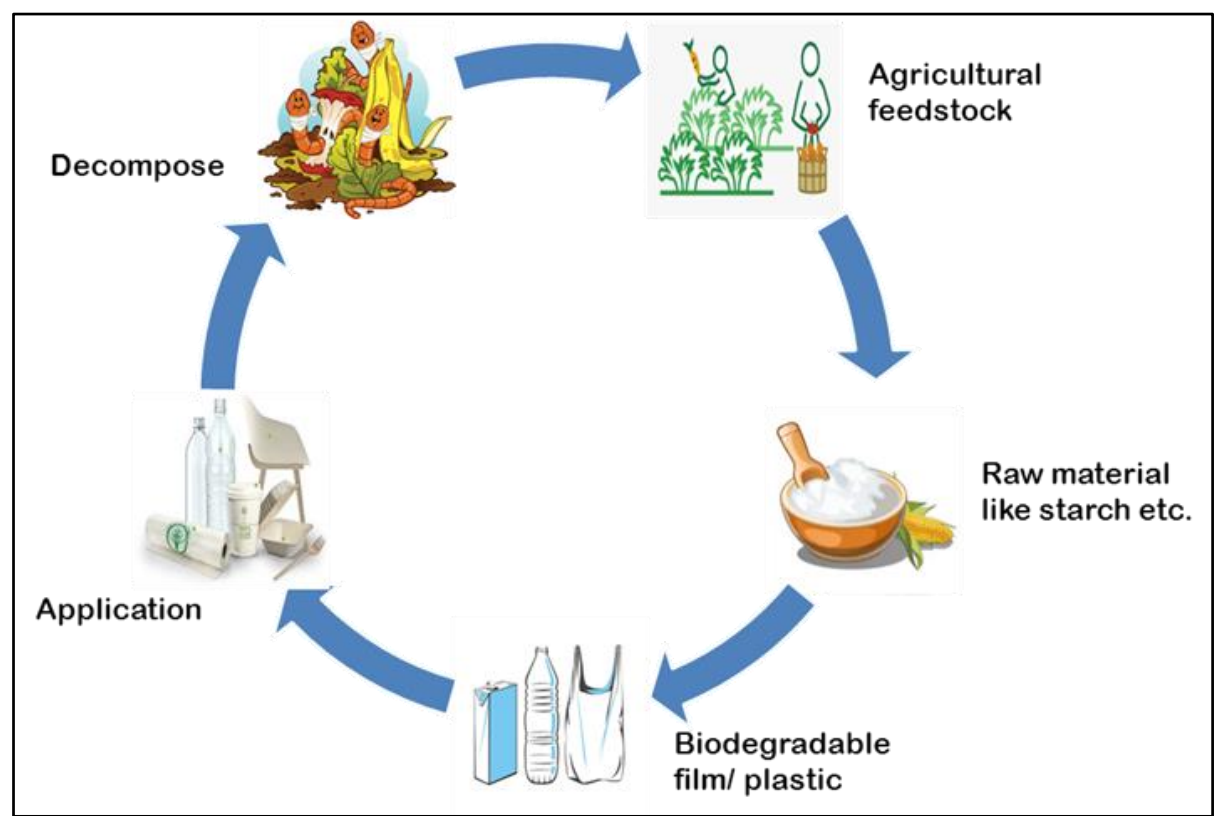

Fig 3: The life cycle of biodegradable film

At present, there are several types of bio-based polymers on the market: same coming from a petrochemical monomer, like certain types of polyester, polyesteramides and polyvinyl alcohol, produced by a different manufacturer, used principally as films or moulding. Four other bio-based polymers are starch materials, cellulose materials, polylactic acid (Polyester, PLA), polyhydroxy acid (polyester, PHA). PHA polymer is a very expensive polymer because it is commercially available in very limited quantities. PLA is becoming a growing alternative as a green food packaging material because it was found that in many situations it performs better than synthetic ones, like PET. (Siracusa et al., 2008) ${ }^{[10]}$

\section{Edible film}

Edible films as the name indicate edible in nature and provide additional nutrition and calories to the consumer. Edible films and coatings are natural polymers obtained from proteins (animal or vegetable), polysaccharides, lipids or combinations of these components. Edible films work as a barrier between food and the surrounding environment. Edible films are generally made up of a particular composition which includes film-forming material, plasticizers, antimicrobial agents, and some additives (Dhumal and Sarkar, 2018) ${ }^{[1]}$. Edible films can be consumed with the products, so there is no package, no dispose of. Even the astronauts can also use this type of edible films in space, which no need to be thrown out. Nowadays edible films are gaining considerable attractions because of the tendency to minimizing the disposes of and helping to combat with pollution Edible film are helpful to protect the commodities from chemical, physical, environmental and microbial changes (fig. 4).

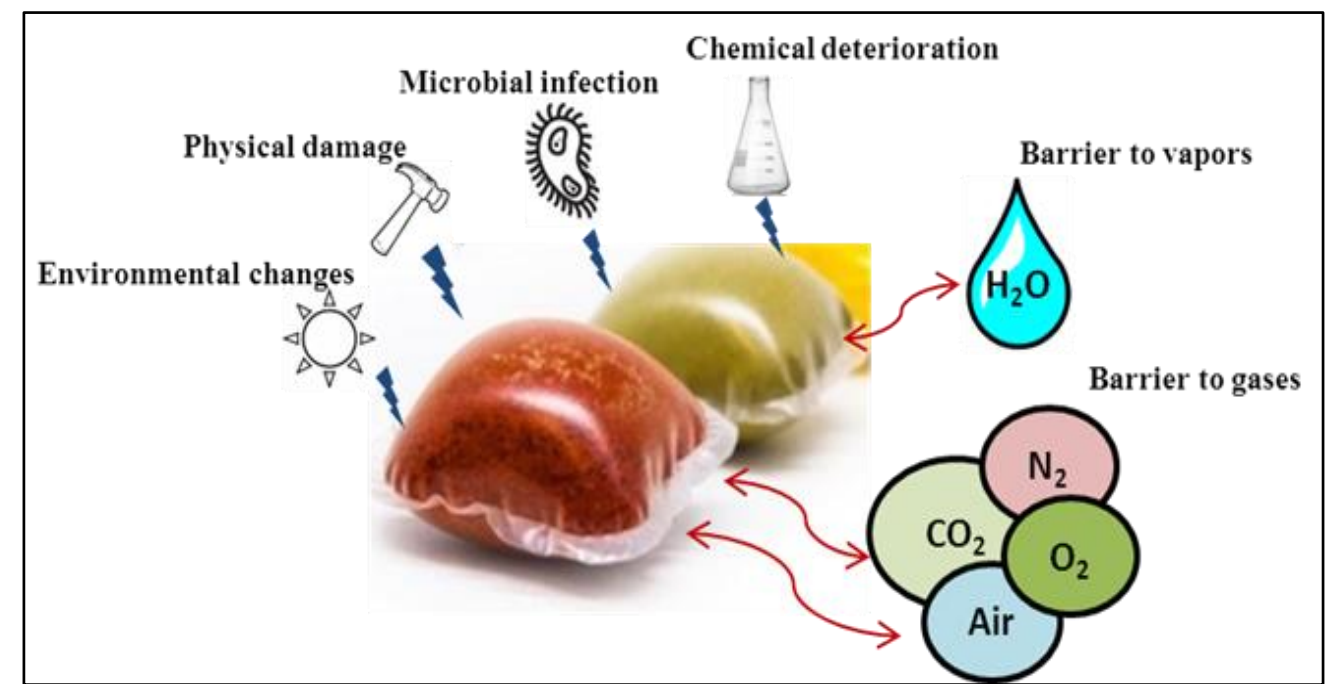

Fig 4: Function and usefulness of edible film and coatings in the food industry

Edible films are mainly prepared from polysaccharides, protein, lipid and its composites. Polysaccharides and proteinbased edible films have a good gas barrier and mechanical properties, but poor water barrier properties. Films made from lipids have good water barrier properties, but poor mechanical properties. Composite films were prepared from protein, polysaccharides and lipids to have both mechanical as well as barrier properties. (Kumari et al. 2017) Edible films are prepared from film matrices extracted from both plant and animal sources. Edible packaging formed from proteins of 
plant origin includes corn zein, wheat gluten, soy protein, peanut protein, quinoa protein, sesame protein whereas keratin, egg white protein, myofibrillar protein, collagen, gelatin, casein and milk whey protein are film formers from animal sources. Starch, cellulose and its derivatives, pectin, chitosan, alginate, carrageenan, pullulan and gellan gum are the main polysaccharide materials tested as edible packaging materials (Galus and Kadzińska 2015). Unlike polysaccharide and protein lipids cannot be used alone for the preparation edible film as they are not biopolymers and are not able to form cohesive films. So, lipids are incorporated in the composite edible film to provide more hydrophobic nature to the film and thereby increasing the water barrier properties substantially. Vegetable oils like olive oil, sunflower oil, rapeseed oil, waxes like carnauba, candelilla, bee wax and synthetic waxes are used in edible film preparation.

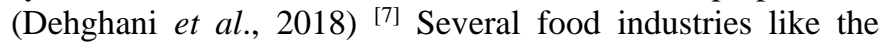
bakery industry, dairy industry, horticulture industry, meatpoultry-sea foods industry are using edible films and coatings for protecting and packaging their products (Pascall and Lin, 2013) ${ }^{[5]}$. So, products of these food industries have the ability to minimize the packaging wastes which are the major part of plastic wastes. Application of edible packaging materials provides some unique advantages like improving the product stability, safety, quality, and convenience for the consumers as well as reduce the packaging waste so act as ecofriendly (Janjarasskul and Krochta, 2010) ${ }^{[3]}$.

\section{Conclusion}

Now a day's plastic became a monster which causing severe harm to our planet earth. Plastic has been created by humans, for human purposes but now it's making harm to an entire living organism directly or indirectly. Out of $10.5 \mathrm{Mt}$ of total plastic India produced, 6-million-ton plastic waste every year which possess a major problem for solid waste management. Manufacturing, as well as degradation of these polymers, contribute to various ecological problems including white pollution (pollution caused by the plastic disposal/waste), emission of toxic compounds such as Carbon Monoxide, Chlorine, Hydrochloric Acid, Dioxin, Furans, Amines and emission of large quantities of greenhouse gasses (GHGs). It is our responsibility to stop this monster, human solution for plastic pollution has been necessary and feasible. Biopolymers including edible and biodegradable film driven innovations will contribute to a sustainable environment, economy, society which will full fill the dream of father of our nation Mahatma Gandhi's Swatch Bharat or Clean India mission.

\section{References}

1. Dhumal CV, Sarkar P. Composite edible films and coatings from food-grade biopolymers. Journal of food science and technology. 2018; 55(11):4369-4383.

2. Galus, Sabina, Justyna Kadzińska. Whey Protein Edible Films Modified with Almond and Walnut Oils. Food Hydrocolloids. 2016; 52:78-86.

3. Janjarasskul T, Krochta, JM. Edible packaging materials. Annual review of food science and technology. 2010; 1:415-448.

4. Kumari, Madhu, HimadriMahajan, Robin Joshi, Mahesh Gupta. Development and Structural Characterization of Edible Films for Improving Fruit Quality. Food Packaging and Shelf Life, 2017.
5. Pascall MA, Lin SJ. The application of edible polymeric films and coatings in the food industry. J Food Process Technol. 2013; 4(2): e116.

6. PlasticsEurope, Plastics-the facts 2018: an analysis of European plastics production, demand and waste data. Retrieved from, 2018. https://www.plasticseurope.org/downloadfile/force/2387/ 319

7. Dehghani SSV, Hosseini, JM. Regenstein Edible films and coatings in seafood preservation: A review Food Chemistry. 2018; 240:505-513

8. Steinmetz Z, Wollmann C, Schaefer M, Buchmann C, David J, Tröger J, et al Plastic mulching in agriculture. Trading short-term agronomic benefits for long-term soil degradation? Science of The Total Environment. 2016; 550:690-705.

https:// doi.org/10.1016/j.scitotenv.2016.01.153

9. Thompson RC, Swan SH, Moore CJ, vom Saal FS. Our plastic age. Philosophical Transactions of the Royal Society B: Biological Sciences. 2009b; 364(1526): 19731976. https://doi.org/10.1098/rstb.2009.0054.

10. Siracusa V, Rocculi P, Romani S, Rosa MD. Biodegradable polymers for food packaging: A review Trends in Food Science \& Technology. 2008; 19(12):634-643. 